\title{
Study of Durability of Siliceous Sand Based Mortars in Togo, and of Binder of Plastic Bags of the Kind "Voltic": Hydrocarbons' Effect
}

\author{
Kossi Bollanigni Amey1*, Ouro-Djobo Samah'2, Kouma Neglo', Abalo P'Kla1, \\ Komi Mawutodzi Sounsah ${ }^{3}$, Komlan Amoussou ${ }^{3}$, A. Vianou ${ }^{4}$ \\ ${ }^{1}$ Ecole Nationale Supérieure d’Ingénieurs (ENSI), Université de Lomé (UL), Lomé, Togo \\ ${ }^{2}$ Centre de la Construction et du Logement (CCL), Lomé, Togo \\ ${ }^{3}$ Equipe de Recherche et Développement (ERDF), FORMATEC, Lomé, Togo \\ ${ }^{4}$ Laboratory of Study and Research, Industrial Technologies University of Abomey, Cotonou, Benin \\ Email: *ameykoss3@yahoo.fr, *formatec03@yahoo.fr
}

How to cite this paper: Amey, K.B., Samah, O.-D., Neglo, K., P'Kla, A., Sounsah, K.M., Amoussou, K. and Vianou, A. (2018) Study of Durability of Siliceous Sand Based Mortars in Togo, and of Binder of Plastic Bags of the Kind "Voltic": Hydrocarbons' Effect. Journal of Minerals and Materials Characterization and Engineering, 6, 25-37. https://doi.org/10.4236/jmmce.2018.61003

Received: November 25, 2017 Accepted: December 26, 2017 Published: December 29, 2017

Copyright (c) 2018 by authors and Scientific Research Publishing Inc. This work is licensed under the Creative Commons Attribution International License (CC BY 4.0).

http://creativecommons.org/licenses/by/4.0/

\begin{abstract}
The present study aims at environmental protection through the use of plastic wastes in the production of mortar. The behavior of siliceous sand-based mortars from Togo and binders of plastic bags of the kind "voltic" is analyzed. Mortar samples from a mixture of siliceous sand and binder of plastic bags are prepared and subjected to physical and mechanical tests after immersion in the hydrocarbon from 0 hour to 504 hours. The result demonstrates that hydrocarbons have no influence on mechanical properties of mortars for an immersion time below 3 hours. Between 3 hours and 24 hours the presence of hydrocarbon increases their physical and mechanical properties. After 24 hours mortars generally lose the mechanical properties of around $8 \%$ to $24 \%$ due to the loss of viscosity and cohesiveness of the binder caused by the fuel. The behavior in the face of hydrocarbons shows that the material can be used in the surface of roads by carefully avoiding that hydrocarbons remain on the roads for a period of time beyond 24 hours.
\end{abstract}

\section{Keywords}

Mortar, Plastic Bags, Siliceous Sand, Hydrocarbon, Physical and Mechanical Properties

\section{Introduction}

Nowadays, all plastic materials account for $4 \%$ of the use of oil from around the world and plastic packaging materials represent alone $1.5 \%$. The household 
packaging materials represent around $20 \%$ of the load of household waste [1]. The management of the end of their life is handled in various ways: valorization of the material, energy valorization, and organic valorization by way of composting and biodegradation [2].

In Togo, plastic packaging bags of sold cold water commonly called "pure water" are largely widespread. Many companies produce and supply cold plastic water from around the country. After they become useless, they are thrown everywhere on the streets, roads, and on wild dumps, etc. The big problem is that they are not biodegradable and therefore represent a source of pollution, unhealthy sanitary conditions and a danger for animals. Their combustion also causes acidification of the atmosphere and photochemical oxidation. In order to deal with this scourge, the Togolese government, through its order No. 2011003/PR of 5 January 2011, banned the import and the use of such non-degradable plastic bags that are unfortunately still used. In the face of this situation, a solution for the protection of environment-still being polluted-might be their use in the concrete. In fact, concrete composed of gravel, sand, cement and water is widely used in the construction works. As for sand, it is also used in wall mortars as well as in reinforced concrete works for some part of buildings, roads, bridges, etc.

In their experimental works, Amey et al. [3] analysed physical and mechanical properties of mortars based on siliceous sand and binders of plastic bags melted for binder dosages from $7 \%$ to $28 \%$. Samples are immersed in hydrocarbon solution from $0 \mathrm{~h}$ to $96 \mathrm{~h}$ and subjected to compression, bending and crazing tests. The results indicate optimal resistances in compression $(\sigma c)$, crazing $(\tau \mathrm{d})$, traction by bending $\left(\sigma_{\mathrm{f}}\right)$, traction by crazing $\left(\sigma_{\mathrm{d}}\right)$ for binder dosages varying between $16 \%$ and $22 \%$ and that the sample is water-resistant for binder contents beyond $18 \%$.

In order to contribute to the end-of-life management of "voltic" plastic bags, which are the most available in Togo through their valorization, we propose, through this study, to analyze the behavior of siliceous sand-based mortar and binders of plastic bags melted by the heat of hydrocarbons is analyzed. Physical and mechanical properties of the material are researched in order to find out how it can be used as material for surfacing of roads and streets.

\section{Material, Equipment and Method}

\subsection{Material and Equipment}

Raw materials and the following material have been used for the experimental study:

- hydrocarbon of the kind "super lead-free" from the petrol station called Total in Togo;

- siliceous sand from extraction area of Aképé-Idavé, located at $20 \mathrm{~km}$ north-western of Lomé on the national road No. 3 (see Figure 1);

- Polyethylene plastic packaging bags of water of the brand "voltic" that are 


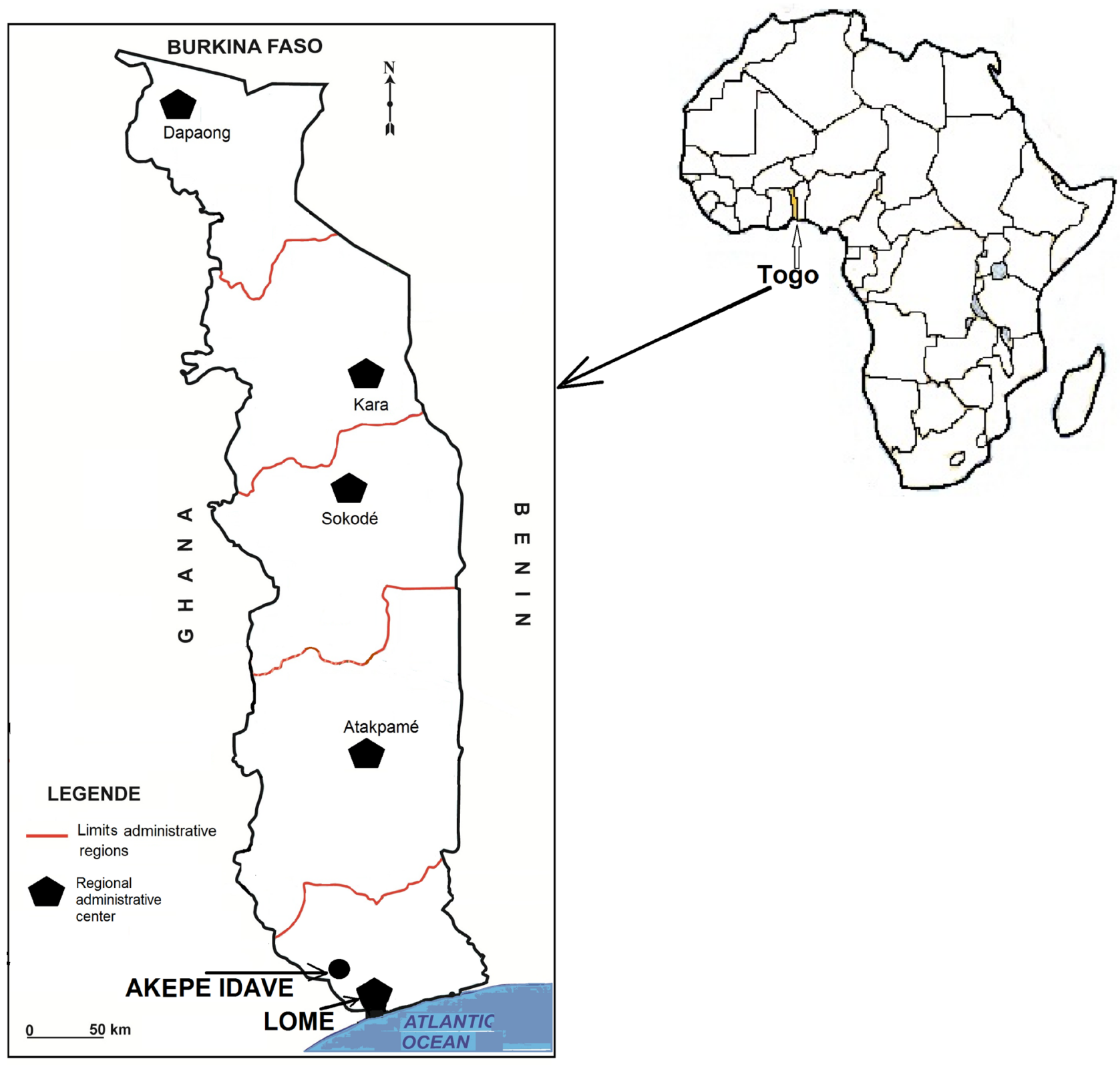

Figure 1. Location of zones of material sample.

produced in Togo (see Figure 2(a));

- podgy mini-mixer (see Figure 2(c)), for melting of plastic bags;

- electronic scale of the brand SILVERCREST of a maximal charge of $5000 \mathrm{~g}$ and of precision $1 \mathrm{~g}$;

- a machine used for shaking up tubes during the test of the equivalent sand of 90 cycles in 30 seconds at automatic stop [4];

- a standard set of AFNOR sieve, with openings in mm: 0.08-0.1-0.125-0.160.2-0.25-0.315-0.4-0.5-0.63-0.8-1-1.25-1.6 and 2 [5] [6] [7];

- prismatic mould of $4 \mathrm{cmx} 4 \mathrm{~cm} \times 16 \mathrm{~cm}$ (see Figure 2(f)) [8];

- a carbon vat;

- a transparent test tube for measuring of absolute density. 


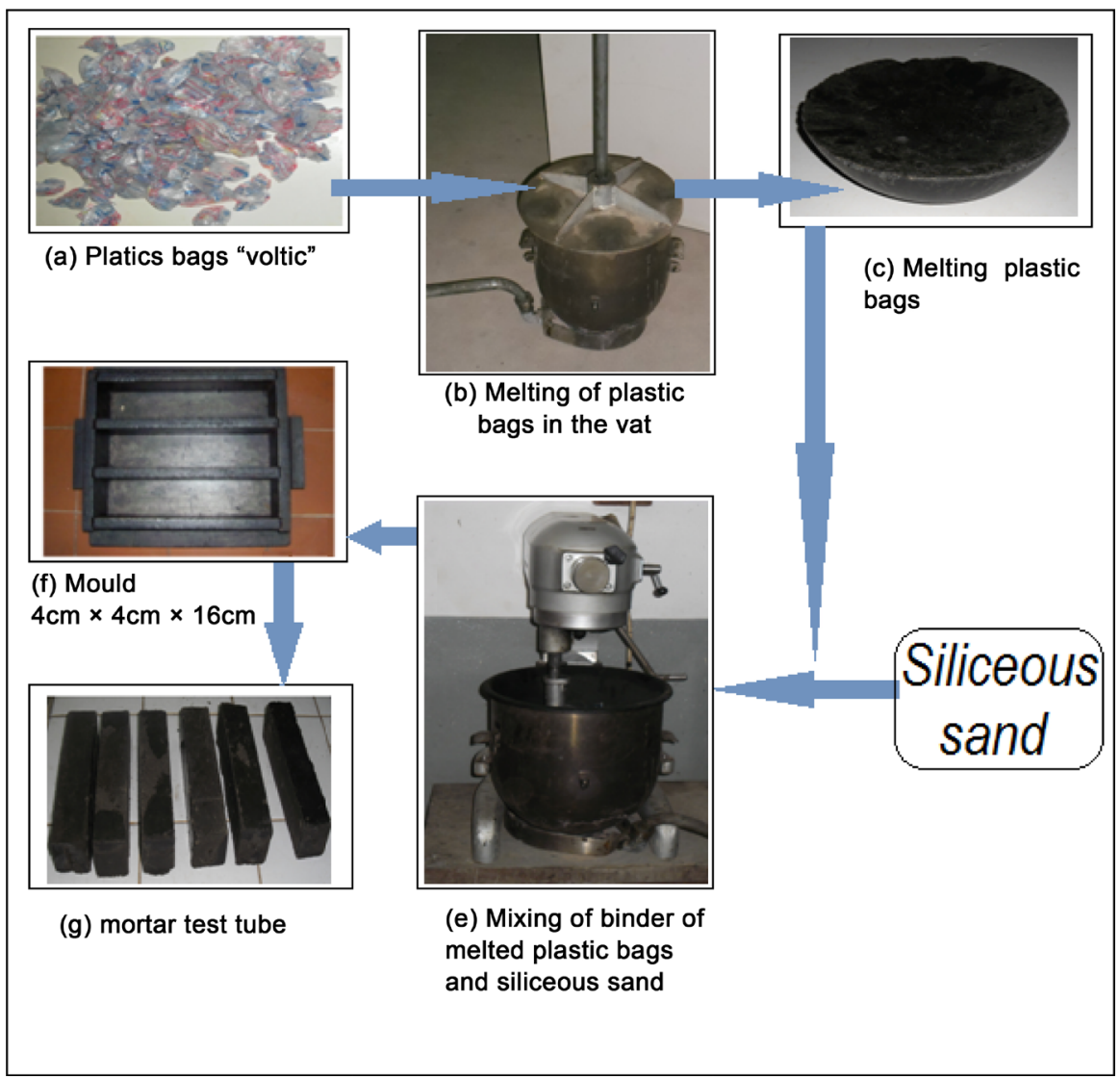

Figure 2. Experimental mechanism of test tubes' preparation.

\subsection{Method}

Plastic packaging bags of water of the brand "voltic" produced in Togoare collected from households in Lomé, capital town of Togo (see Figure 1). Then, they are melted by the system "heating-vat" of the podgy mini-mixer. The sample of sand from the aforementioned extraction area is subject to identification test according to the current standards.

A solid binder sample of the mass $160 \mathrm{~g}$ is immersed in hydrocarbon for 50 days and then placed outside hydrocarbon for ten days. The mass of the sample is measured at every 24 hours.

The different masses of binders that were previously melted are blended with sands in the podgy mini-mixer at a proportioning of $22 \%$ of binder corresponding to an optimum proportioning determined by Amey [3]. The resulting composite materials are then moulded in the $4 \mathrm{~cm} \times 4 \mathrm{~cm} \times 16 \mathrm{~cm}$ mould and then vibrated with a tugging device.

On the whole, 17 samples are produced and freed from mould after 24 hours (see chart $2 \mathrm{~g}$ ) and their initial densities are measured. Twelve (12) samples are then immersed in a vat containing a hydrocarbon of the king "super lead-free" and the other five (5) are conserved outside hydrocarbon to be used as a witness.

The twelve (12) samples, immersed in the vat containing a hydrocarbon, are produced in a series of three (3) after time periods of $24 \mathrm{~h}, 168 \mathrm{~h}, 336 \mathrm{~h}$ and 504 
$\mathrm{h}$ whereas the five (5) witness samples are conserved outside hydrocarbon for $576 \mathrm{~h}$. The masses of the test tubes are measured at every $24 \mathrm{~h}$ up to a constant mass outside hydrocarbon.

The relative density $(r)$ of samples is determined by the following expression:

$$
r=\frac{d_{i}-d_{o}}{d_{o}} \times 100
$$

In this expression, $d_{o}$ represents the density of the sample at the initial state (prior to immersion in hydrocarbon), and $d_{i}$ its density at the measuring $i$.

The mortars' samples are then mechanically tested on the press (see Figure 3), for determining their resistances in traction by bending, compression and traction by crazing after 576 hours of age. The conditions of tests are given in the following manner:

- for bending measuring, the 17 samples undergo bending test three points (see Figure 3); and the bending is measured at halfway.

The constraint of bending $\sigma_{f}$ is given by the expression [9]:

$$
\sigma_{f}=\frac{M}{I} y=\frac{3 P L}{2 a^{3}}
$$

With $M=\frac{P L}{4}$ the bending time, $I=\frac{a^{4}}{12}$ the inertia time and $y=\frac{a}{2}$ the position of the most strained fiber; whereby $P$ is the applied charge, $L$ the distance between the two leans and $\alpha$ the test tube length. In the framework of these works, $L=100 \mathrm{~cm}$ and $a=4 \mathrm{~cm}$.

As for the arrow $\Delta_{f}$, its expression is given by [10]:

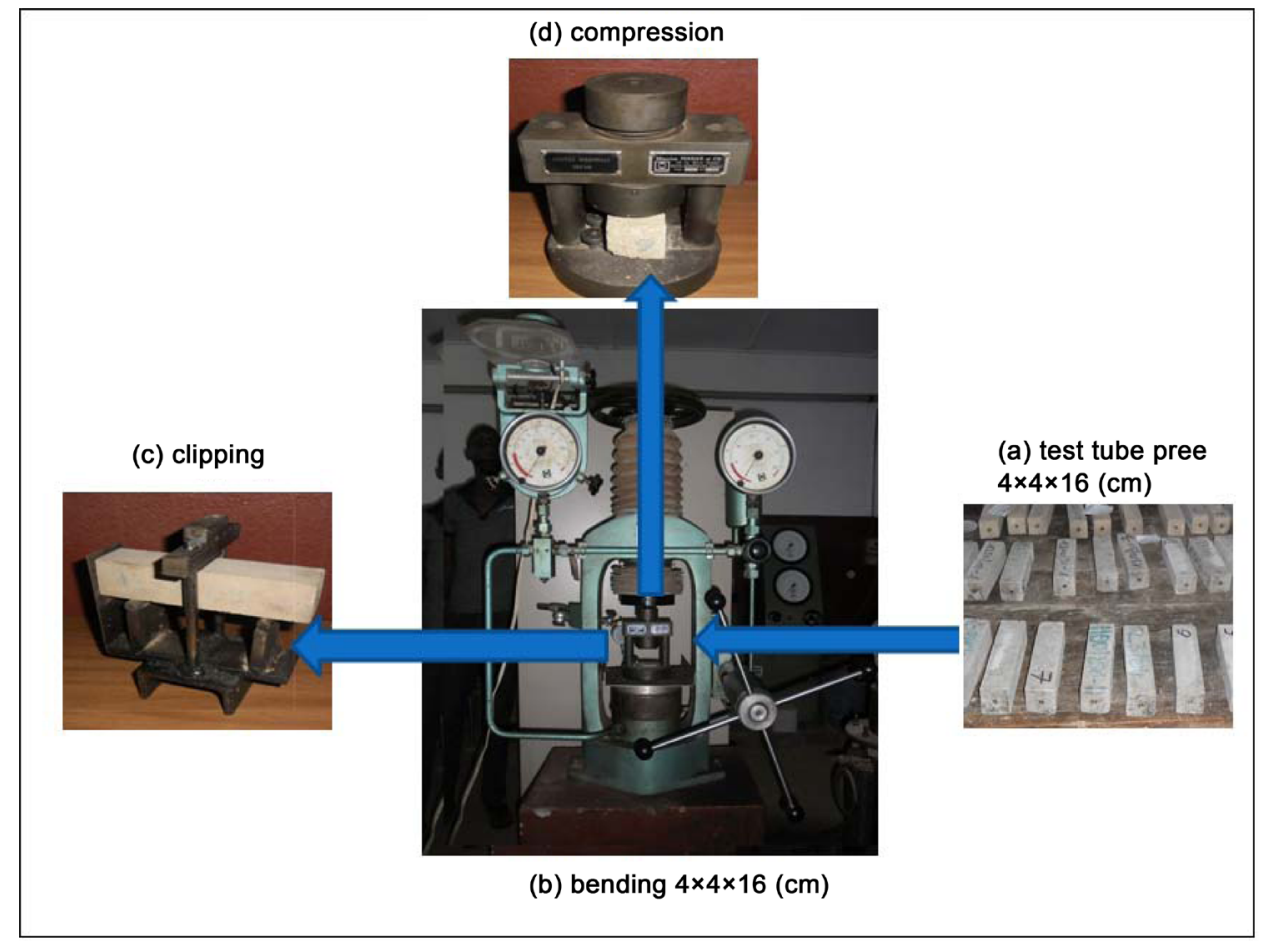

Figure 3. Experiment device for the determining mechanical properties. 


$$
\Delta_{f}=\frac{P L^{3}}{48 E_{f} I}
$$

whereby the modulus of elasticity $\left(E_{f}\right)$ is given by the expression:

$$
E_{f}=\frac{P L^{3}}{4 \Delta_{f} a^{4}}
$$

The parameter of these expressions is defined as previously.

- The half of the halves-samples (17) gained at the end of the bending test has undergone the compression test on the surfaces $4 \mathrm{~cm} \times 4 \mathrm{~cm}$; the strength of braking-up at the compression and the shrinking of the test tube are measured;

By considering the test tubes whose loaded faces are square on side $\alpha$, the expressions of the constraint $\left(\sigma_{c}\right)$, and the shrinking $(\Delta c)$ are provided by [9]:

$$
\sigma_{c}=\frac{P}{a^{2}} \text { and } \Delta_{c}=\frac{P}{E_{c} a}
$$

- The second half of the halves-samples (17) gained at the end of the bending test has undergone the crazing test on a linear contact of $4 \mathrm{~cm}$ on the two opposite surfaces; the braking-up charge and the vertical distortion of the sample are measured;

The expression of the constraint of traction by crazing $\left(\sigma_{d}\right)$ is provided by [11]:

$$
\sigma_{d}=\frac{2 P}{\pi a D}
$$

As for expressions of the constraint of cutting $\left(\tau_{d}\right)$ and the distortion of cutting $\left(Y_{d}\right)$ by crazing, they are provided by:

$$
\tau_{d}=\frac{P}{A}=G_{d} \gamma \text { and } \gamma=\frac{\Delta_{d}}{a}
$$

hence, the expression of the module of elasticity of bending $\left(G_{d}\right)$ provided by:

$$
G_{d}=\frac{P}{a \Delta_{d}}
$$

with $P$ as the applied charge, $\alpha$ the charged linear length $(\alpha=4 \mathrm{~cm}), D$ the distance between the two vertical charges $(D=\alpha=4 \mathrm{~cm})$, and A the charged section.

\section{Findings and Analysis}

Table 1 and Figure 4 provide the findings of the identification test of sand and binder of the used plastic bags.

Table 1. Characteristics of used sand.

Materials Apparent density Absolute density Equivalent of sand (ES) Module of fineness

$\begin{array}{lllll}\text { Sand } & 1.52 & 2.63 & 180 & 1.80\end{array}$




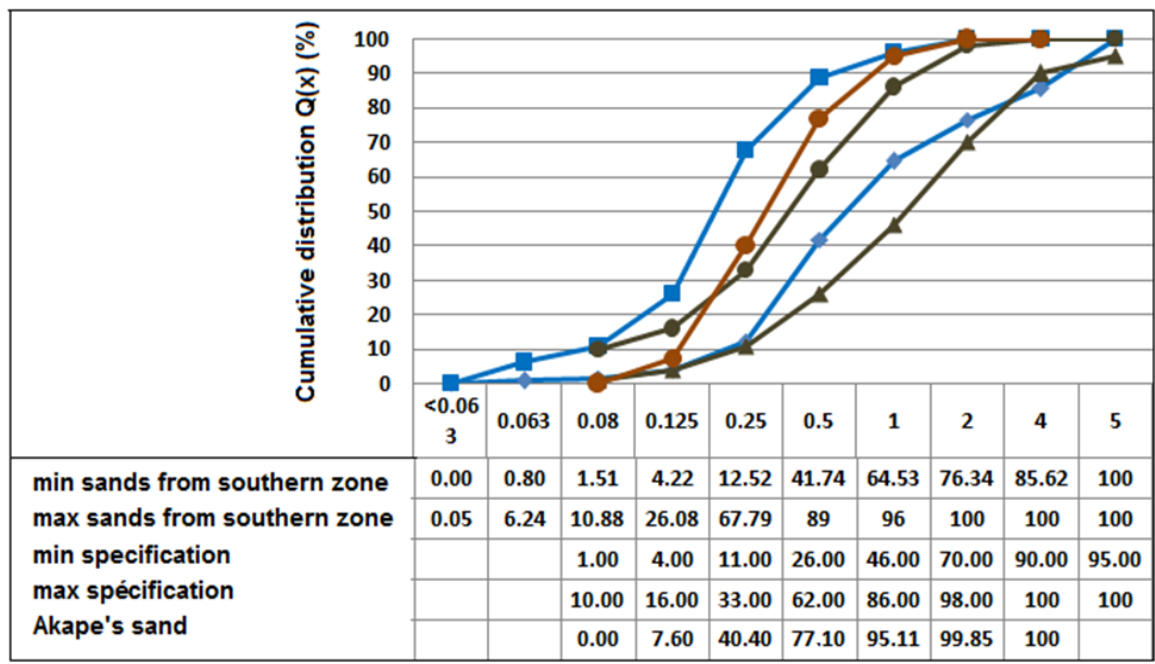

Figure 4. Granulometric curve of used sand [12].

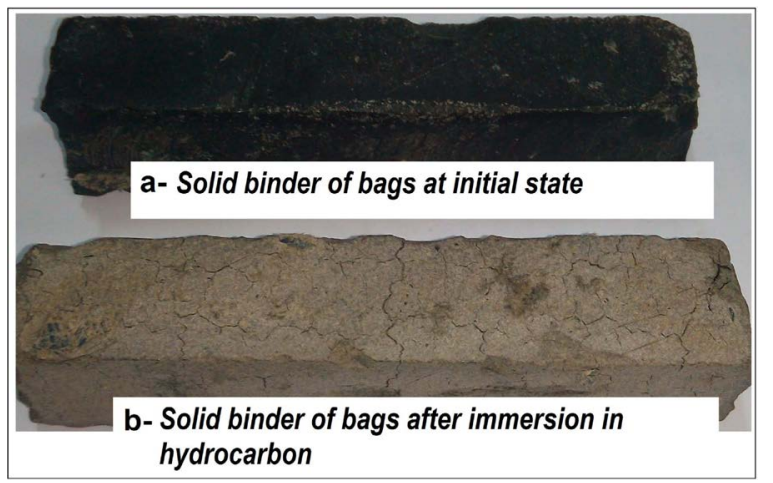

Figure 5. Aspect of sample from the solid binder of plastic bags.

These results show that:

- the sand has the characteristics of a very fine and clayey sand compared with sands from southern region of Togo [4] [12] [13] [14];

- the density of the solid binder from plastic bags is increased as it is soaked in hydrocarbon, but the density sharply drops as soon as the sample is pulled out of hydrocarbon, this is a sign of the degradation of the binder marked by cracks on the facing (see Figure 5). Figures 6-10 provide the results of the tests on the samples after a period of immersion in hydrocarbon.

- Figure 5 and Figure 6 show that the sample of solid binder hardly absorbs hydrocarbon but rapidly rejects it with the appearance of cracks on the facing.

- The results from Figure 7 show that the relative density of mortar "non-immersed" in the hydrocarbon remained constant during 576 hours of conservation. Thus, mortars without hydrocarbon are free from any distortion.

- The density of the samples remains practically unchanged during the first hours (time below 3 hours) of soaking in hydrocarbon; thus, the relative density is practically equal to zero during that period. The rise in the density becomes significant only after three hours of immersion in hydrocarbon (see Figure 8). 


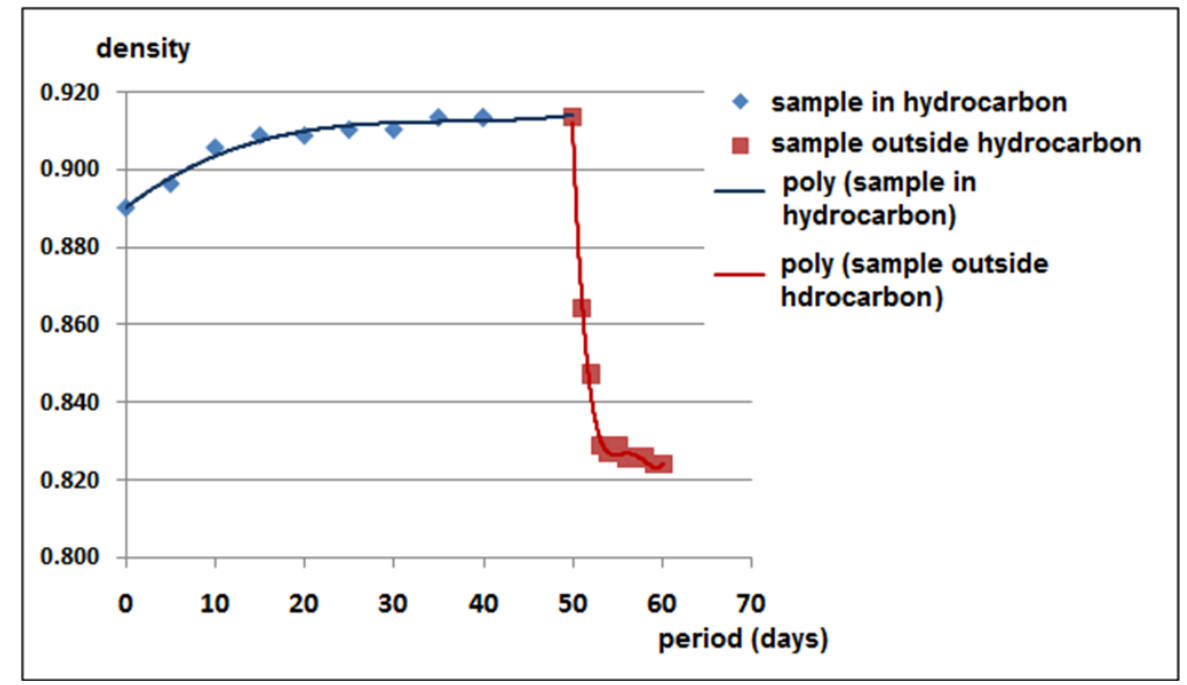

Figure 6. Density of the sample of solid binder of bags according to the period.

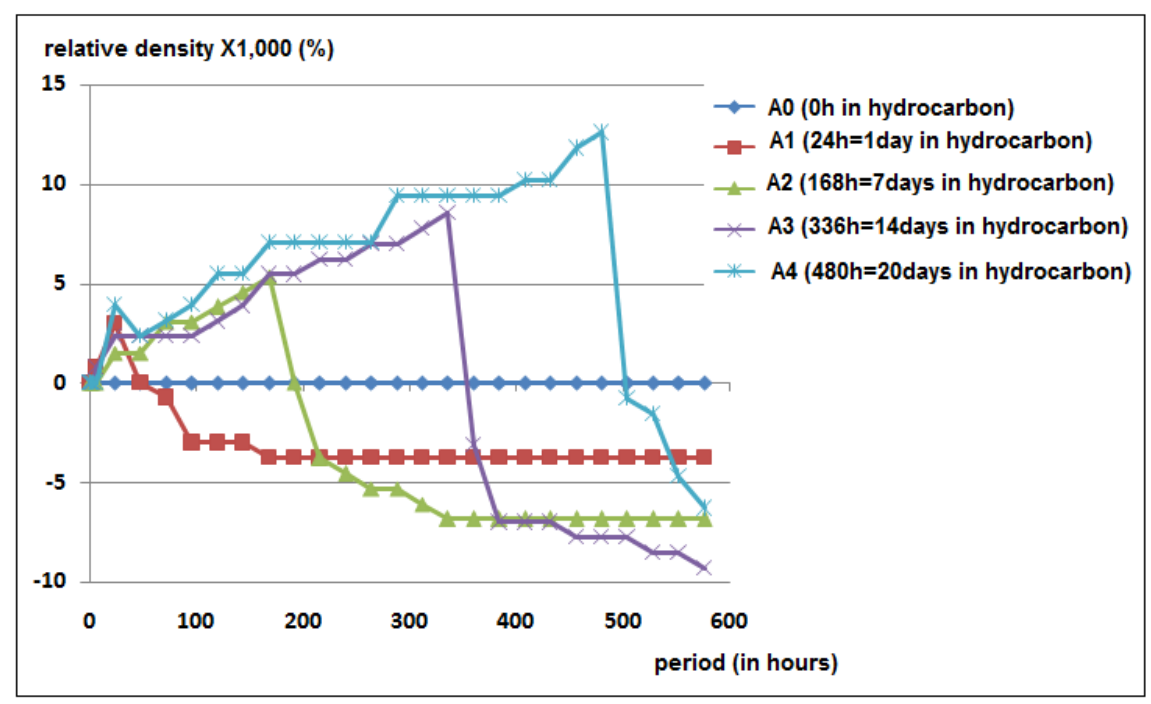

Figure 7. Relative density of test tubes according to the period.
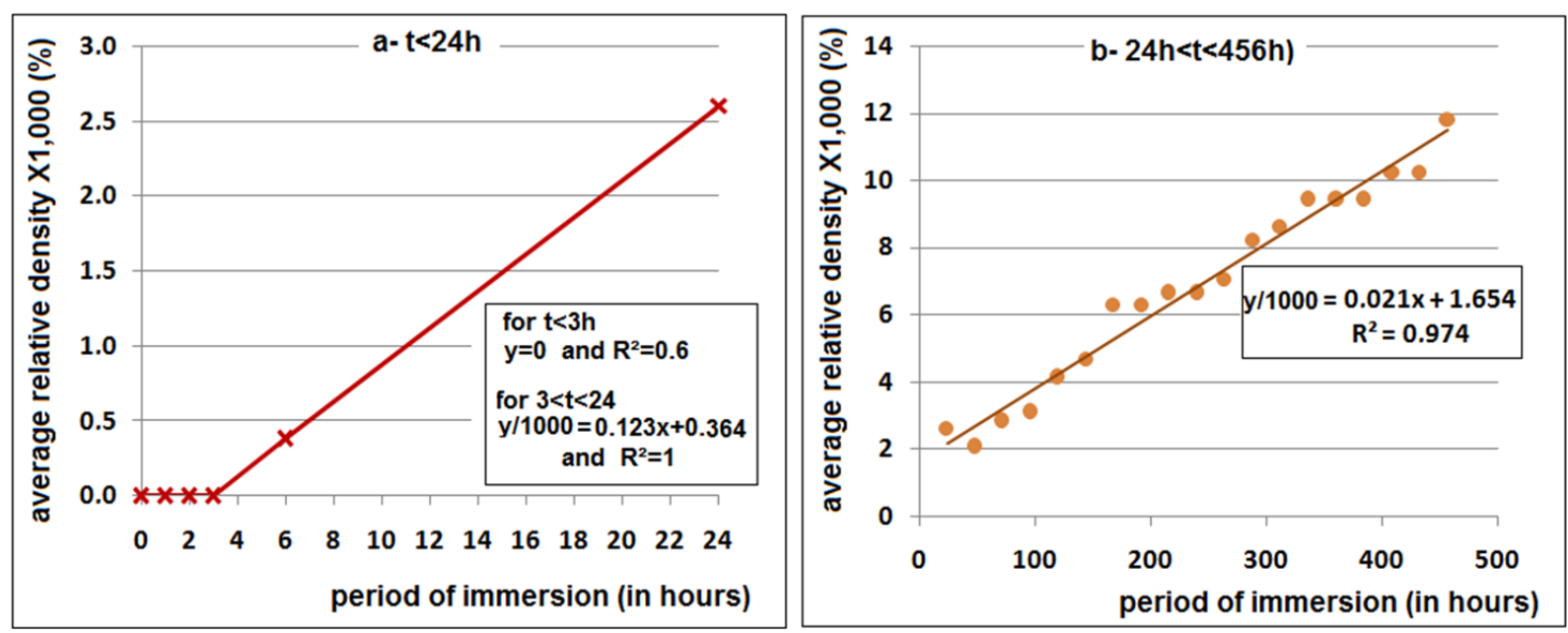

Figure 8. Average relative density according to the period of immersion in hydrocarbon. 


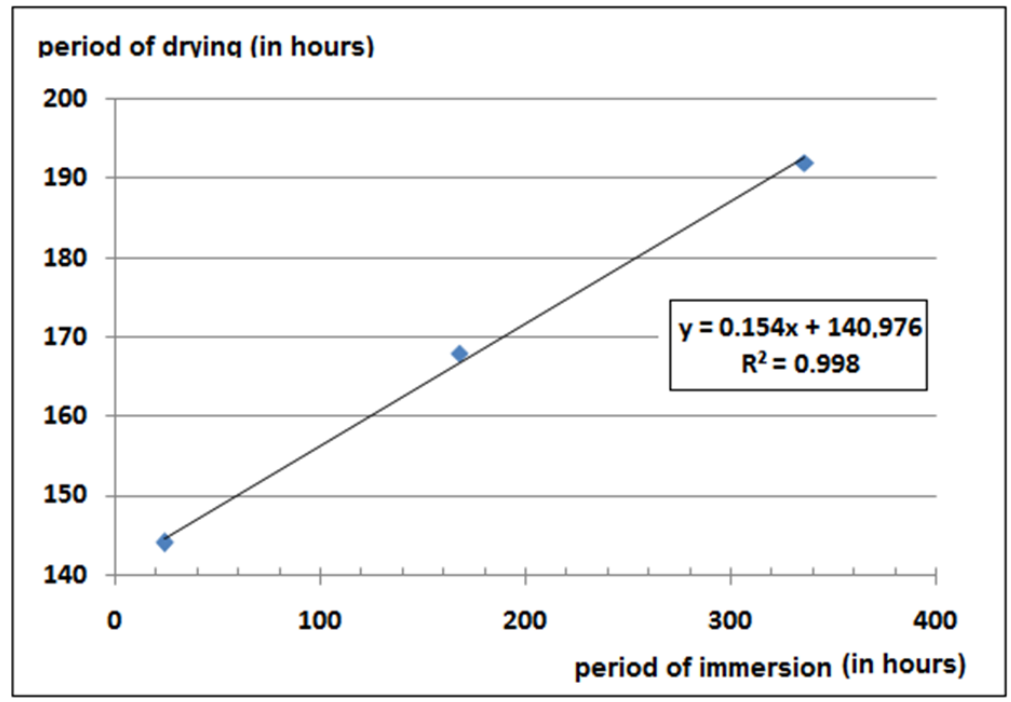

Figure 9. Correlation between the period of drying and the period of immersion in hydrocarbon.

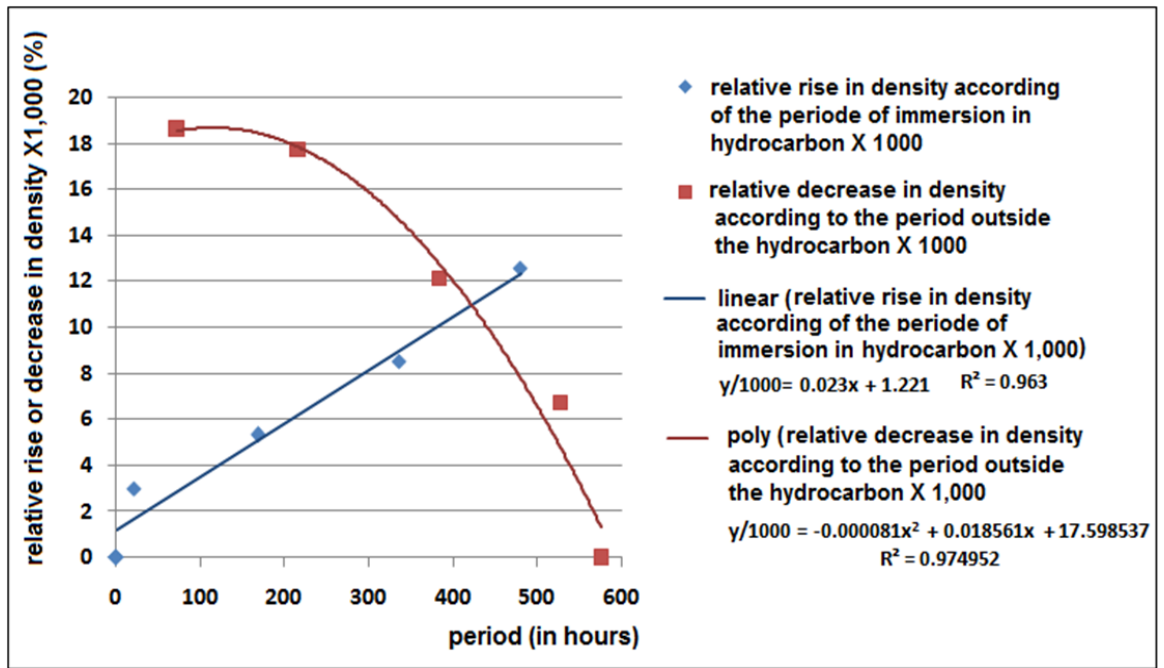

Figure 10. Relative rise and drop in the density based on past periods in/out of hydrocarbon.

- The density of the samples grows with the time of immersion in hydrocarbon and drops as soon as they come out of hydrocarbon and take up afterwards their initial value after 24 hours (see Figure 7). The relative variation of the density is therefore zero after these 24 hours corresponding to a drop of $100 \%$. Beyond the 24 hours, the density gets lower than the initial value no matter the length of time they remain in hydrocarbon and the relative density (r) is then negative (see Figure 7). It stabilizes after a period of 144 hours, 168 hours and 192 hours for relative time periods of immersion in hydrocarbon of 21 hours, 168 hours and 336 hours.

- The relative density (r) linearly grows with the time of immersion of the samples in hydrocarbon. It falls down in a parabolic way outside hydrocarbon with this time of immersion (see chart 10). The smoothing curves of 
these experiments for characterizing each behavior are provided by:

$\circ$ for absorption of hydrocarbon according to the period of immersion of the mortar:

$$
\begin{gathered}
r_{\alpha 1}=0 \text { and } R^{2}=0.6 \text { for } t \leq 3 \\
r_{\alpha 2}=(123 t+364) \times 10^{-6} \text { and } R^{2}=1 \text { for } 3 \leq t \leq 24 \\
r_{\alpha 3}=(21 t+1654) \times 10^{-6} \text { and } R^{2}=0.974 \text { for } 24 \leq t \leq 456
\end{gathered}
$$

In these equations, $r_{a i}$ represents the relative density for a length of time of immersion $t$ (in hours) in hydrocarbon and $R^{2}$ the coefficient of determination.

$\circ$ for the time of drying $t_{s}$ (in hours) outside hydrocarbon according to the time of

Immersion $t_{i}$ (in hours) of mortar in hydrocarbon:

$$
t_{s}=0.154 t_{i}+140.976 \text { and } R^{2}=0.998
$$

$\circ$ the equations of the growing relative density $\left(r_{a}\right)$ and of the falling relative density $\left(r_{p}\right)$ according to the length of time of immersion in hydrocarbon $t$ (in hours):

$$
\begin{gathered}
r_{\alpha}=(23 t+1221) \times 10^{-6} \text { and } R^{2}=0.963 \\
r_{p}=\left(-0.081 t^{2}+18.561 t+17598.537\right) \times 10^{-6} \text { and } R^{2}=0.974952
\end{gathered}
$$

The rise in the density during the immersion in hydrocarbon means that the samples absorb hydrocarbon and the drop in the density is due to the loss of absorbed hydrocarbon. The negative values of relative densities indicate that hydrocarbon caused a destruction of mortar by separating the binder of aggregates before it evaporates.

The mechanical characteristics of mortars are provided by Figure 11 in relation to the time of immersion in hydrocarbon:

The data from this chart show that normal constraints in compression, in traction by bending, in traction by crazing and inclipping by crazing grow suddenly with the time of immersion in hydrocarbon. They rise and fall then, with optimal points at periods of immersion in hydrocarbon of 168 hours except for the constraint of compression for which the optimal time of immersion is 24 hours.

The growth can be explained by the action of hydrocarbon in the viscosity of binder helping with a heightened adherence of this binder to aggregates. As for growth, it would be due to an excess of thinner (fuel) leading to a dissolution of the binder, making it too fluid, weakening then cohesion between the two materials. The presence of cracking on the facing of the sample of the solid binder (see Figure 5) and its loss in weight outside hydrocarbon (see Figure 6) indicate this behavior of degradation of properties of cohesiveness and adhesiveness of this sample of solid binder.

The curves of smoothing characterizing the mechanical behavior according to periods of time $t$ (in hours) of immersion in hydrocarbon are the following: 

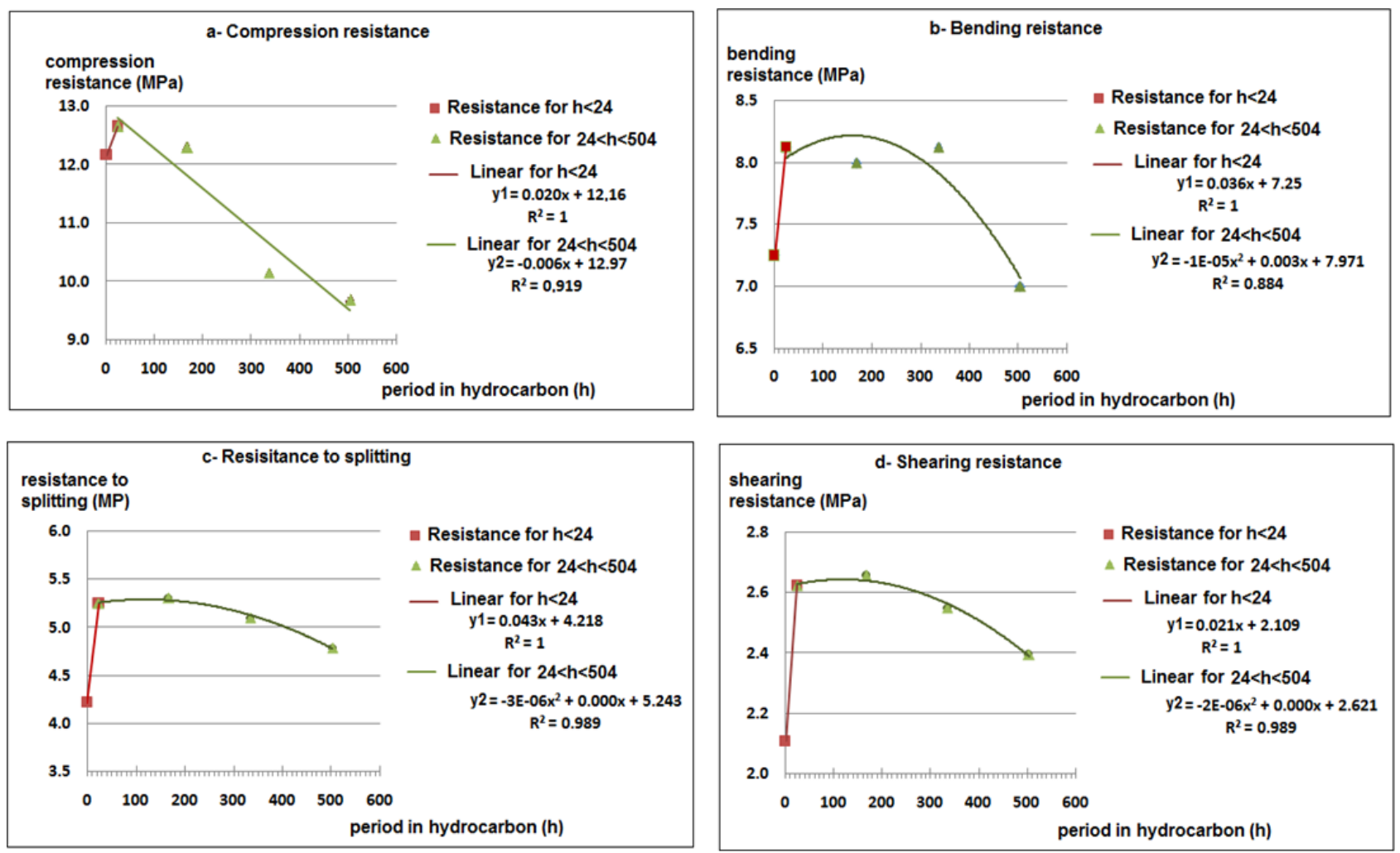

Figure 11. Resistance according to periods of time in hydrocarbon.

o for resistance of compression $\sigma_{c}$ (in $\mathrm{MPa}$ )

$$
\begin{gathered}
\sigma_{c}=-0.020 t+12.16 \text { and } R^{2}=1 \text { for } t<24 \\
\sigma_{c}=-0.006 t+12.97 \text { and } R^{2}=0.919 \text { for } t<24
\end{gathered}
$$

○ for resistance of bending $\sigma_{f}($ in $\mathrm{MPa})$ :

$$
\begin{gathered}
\sigma_{f}=-0.036 t+7.25 \text { and } R^{2}=1 \text { for } t<24 \\
\sigma_{f}=-0.00005 t^{2}+0.003 t+7.971 \text { and } R^{2}=0.884 \text { for } t<24
\end{gathered}
$$

o for resistance of crazing $\sigma_{d}($ in $\mathrm{MPa})$ :

$$
\begin{gathered}
\sigma_{d}=0.043 t+4.218 \text { and } R^{2}=1 \text { for } t<24 \\
R^{2}=0.989 \text { and } R^{2}=0.989 \text { for } t<24
\end{gathered}
$$

o for resistance of clipping $\left(\tau_{d}\right.$ in $\left.\mathrm{MPa}\right)$

$$
\begin{gathered}
\tau_{d}=0.021 t+2.109 \text { and } R^{2}=1 \text { for } t<24 \\
\tau_{d}=-0.06 t^{2}+0.000 h+2.621 \text { and } R^{2}=0.989 \text { for } t<24
\end{gathered}
$$

From these equations $R^{2}$ is defined as previously.

\section{Discussion}

The mortar is very watertight by a dosage of $22 \%$ [3]. So, hydrocarbon hardly goes through it; its relative density is therefore null during the first three hours. After this period hydrocarbon breaks up the binder of plastic bags acting as a 
solvent [15]. For a time of weak immersion, (lower than 24 hours) mortar absorbs hydrocarbon whose quantity corresponds to the one required for a sufficient viscosity of binder, generating a good adhesion to aggregates. This phenomenon explains the increase in mechanical resistances (compression, bending, crazing and clipping) of samples.

For important periods of immersion in hydrocarbon, mortars absorb more fuel; this is what explains the high density. However, as soon as they come out of hydrocarbon, they lose suddenly the absorbed fuel (less than 24 hours) and their relative density becomes negative by around 144 hours, corresponding to a density lower than the initial value. This negative density shows that the hydrocarbon acted as a thinner in relation to the binder of plastic bags by breaking it up into molecules and by coming in between them. This caused a weakening of links of binder-aggregates. The new binder composed of binder of plastic bags and fuel "super lead-free" could evaporate, leading to a fall corresponding to a relative and negative density (r) of mortars so far as the samples have come out of hydrocarbon. The longer samples remained in hydrocarbon, the more this binder loses its cohesiveness and adhesiveness, the more evident is the phenomenon of separations of molecules and the separation of the binder from aggregates; so, the mortars lose their mechanical characteristics. This phenomenon justifies the increasingly weak resistances of mortars (loss of resistance from $8 \%$ to $24 \%$ ) when they remain longer in hydrocarbon, for adhesiveness is inexistent between the binder and the aggregates.

\section{Conclusion}

The aim of the study was to help with the valorization of plastic bags "out of use" through the study of the behavior of the mortars gained from the mixing of siliceous sand of Togo and binder of plastic bags of the kind "voltic" with regard to hydrocarbons. Results have showed that hydrocarbons have no influence on the mechanical properties of mortars for length of time of immersion shorter than 3 hours. Between 3 hours and 24 hours of immersion, hydrocarbons contribute to the rise in the mechanical and physical characteristics of mortars. After a period of 24 hours, mortars generally lose their mechanical properties. The behavior toward hydrocarbons shows that the material can be used for the surface of roads. Nevertheless, work needs to be done to reduce the negative effect of the long-term (over 24 hours) stay of hydrocarbons on roadways.

\section{Acknowledgements}

This work could not have been carried out without the logistic and financial support from FORMATEC we express our sincere gratitude to.

\section{References}

[1] Conseil National de l'Emballage (2009) Emballages Compostables \& matériaux plastiques dits "biodégradables" issus de ressources renouvelables. Note de position du 
Conseil National de l'Emballage.

[2] Doublie, G. and Sorgho, O. (2009) Valorisation des déchets de sachets plastiques application dans les villes subsahariennes.

http://www.envirobf.org/dossiers-speciaux/14

[3] Amey, K.B., Neglo, K., Samah, O.D., Kouto, A.Y. and P'Kla, A. (2014) Étude expérimentale de la formulation de mortier a base de sable silteux du Togo et de liant de sachets plastiques type "voltic". Journal Afrique Science, 10, 53-69.

http://www.afriquescience.info

[4] AFNOR. Normes NF EN 12620. (2002) Granulats pour béton. 54 p.

[5] AFNOR. Normes NF EN 933-2. (1996) Essais pour déterminer les caractéristiques géométriques des granulats, Partie 2: Détermination de la granularité-Tamis de contrôle, dimensions nominales des ouvertures. $12 \mathrm{p}$.

[6] AFNOR. Normes NF ISO 9276-1. (1998) Représentation de données obtenues par analyse granulométrique-Partie 1: Représentation graphique. $13 \mathrm{p}$.

[7] AFNOR. Normes NF EN 933-8 (1999) Essais pour déterminer les caractéristiques géométriques des granulats, Partie 8: Evaluation des fines-Equivalent de sable. $14 \mathrm{p}$.

[8] Dreux, G. (1981) Nouveau guide de béton. Edition Eyrolles, Paris, 329 p.

[9] Agati, P., Lerouge, F. and Rossettom (2008) Résistance des matériaux. Edition Dunod, Paris.

[10] Picard, A. (1992) Analyse des structures. Editions Beauchemin Itée, Canada.

[11] Tahenni, T. (2006) Fissuration en béton avec référence particulière au béton à haute performance. USTHB, Algerie.

[12] Amey, K.B., Neglo, K., Tamba, S., Johnsona, K.C., Kouto, Y.A. and Nayo, E. (2014) Caractérisation physique de sables silteux au Togo. Journal Afrique Science, 10, 53 69. http://www.afriquescience.info

[13] Lefeub and Francyo (1999) Module de finesse d'un sable. Fiche Technique de CERIB, $2 \mathrm{p}$.

[14] GPB (Groupement Professionnel de Bitume) (2005) Bitume-Aménager, Construire, Innivé. Numéro spéCial-1.

[15] AFNOR (2002) Normes NF EN 12620. Granulats pour béton. 54 p. 